\title{
4. The welfare dimension: understanding trans(national) solidarity in Europe
}

\section{Simone Baglioni and Tom Montgomery}

\subsection{INTRODUCTION}

In times of crisis and polarisation, the value of being committed to mutual support, particularly in the absence of any legal obligations to do so or communitarian connections (Musso, 2015; Supiot, 2015) is one of the crucial components that can hold society together, along with welfare state policies and, more broadly, public interventions. We can best comprehend this type of support through the concept of solidarity and we can most easily recognise it through its organisational expressions, either formal or informal, via collective action. These organisational expressions of solidarity provide the vehicles through which collective action can reach beyond divisions and strive towards a common goal that brings benefits to vulnerable groups at different geographical levels, whether that is neighbourhoods, countries, continents or beyond.

In this chapter, we explore how civil society organisations (CSOs) operate as vehicles of solidarity with three groups of vulnerable people: the unemployed, disabled people, and migrants/refugees. Our focus is on those organisations which, through involvement in service delivery across a range of policy domains primarily connected to welfare state provision, promote an idea of solidarity based on the sharing of common resources to address salient needs at a time of economic crisis. However, we will also consider the advocacy capacity of civil society and their work to support people's engagement across a range of policy-oriented activities through direct action and forms of mobilisation, while maintaining our primary focus on welfare state service-oriented CSOs. In fact, our interest in the intervention of civil society organisations in the welfare state supply chain stems from our recognition of the critical role that the welfare state plays in the promotion of solidarity as a set of collectively funded actions to support people across a range of needs. Moreover, we focus on the 
welfare state because civil society organisations have become increasingly important actors in the implementation and sometimes even in the design of welfare state services across Europe. These developments have led to a body of literature that speaks to the existence of a 'welfare mix' (Evers, 1995) in order to illustrate the intertwinement of public sector and civil society actors in the design and delivery of welfare state policies. More recent developments in both research and practice has led to the emergence of the concept of co-production in which the welfare state is characterised as being in formal partnerships with civil society or third sector actors to meet the needs of a variety of service users (Brandsen et al., 2014).

Our analysis took place during a period of economic and financial strain in Europe, when public resources have been curtailed by policies designed to reduce public budgetary deficits while societal needs have increased, in particular the needs of the three groups which form the focal point of our research. Unemployment increased in many European countries as a result of the 2008 onward economic and financial crisis, disabled people have seen their demands remaining more and more unanswered due to reduction in public expenditures (Montgomery and Baglioni, 2018), while the number of refugees has grown in some countries as a consequence of the civil war in Syria, as well as the broader political instability in the Middle East and the Horn of Africa. Against this backdrop, it is worth considering whether the role of civil society has contributed towards keeping welfare state solidarity alive, and whether there have been nuanced variations in these forms of solidarity among European countries.

Furthermore, we are interested in exploring if such a civil society-driven solidarity spans across boundaries, that is, if it qualifies as a transnational, cross-European form of solidarity. The existence of organised transnational solidarity remains contested in the academy. Several scholars have contributed critical perspectives regarding the existence and functioning of a truly European sphere of solidarity: most of this criticism has focused on the relationship between the institutions of the European Union and the weak capacity of organisations to shape EU policies and discourses in comparison to the ways in which they have been shaped by the EU. One critique has focused on the way EU institutions have opportunistically used civil society, that is, by confining solidarity organisations to an ancillary role of policy implementation rather than policy innovation and design. The existence of a genuine European civil society has been called into question from those perceiving EU funding mechanisms to have become a trap which contributes towards silencing the voice of solidarity organisations and one where only tame organisations are allowed to operate (Warleigh, 2001). Others have pointed to a European sphere of solidarity being de facto reduced to a Brussels-based elite of professionals 
primarily devoted to lobbying (Greenwood, 2007). Similarly, scholars have also criticised the selection bias operated through the modus operandi of European institutions according to which only the most resourceful and financially astute organisations succeed (Lahusen, 2014; Baglioni, 2015). Finally, there are also scholars who consider the question regarding the existence of a European sphere of solidarity as a bogus question, given that most organisations are nationally embedded rather than operating across Europe (van Deth, 2008). Following such critical voices, one would be inclined to conclude that official policy rhetoric about the existence of a transnational or European-wide sphere of solidarity qualifies as a participatory myth (Smismans, 2003). The latter understanding of the shortcomings of a transnational or pan-European civil society might be confirmed by the type of analysis, such as ours, which focuses on the activation of civil society in the field of the welfare state, given that welfare states have remained primarily nationally bound. However, should we find evidence revealing truly transnational forms of activism occurring in this area, we might then provide vindication in favour of those arguing that the European Union has had a transformational effect on national welfare states, leading to their Europeanisation or destructuring/restructuring (Leibfried and Pierson, 1995; Ferrera, 2005).

Any potential transnationalisation of civil society may have occurred, paradoxically, as a consequence of the economic and financial crisis that has affected Europe since 2008 and the arrival of would-be migrants and refugees on the southern shores of the continent in 2015-16, due to civil war in Syria and political destabilisations in the Middle East. These phenomena have in fact summoned the potential existence of a transnational sphere of solidarity in Europe. Mobilised through collective actions to support people in desperate need or to make claims for different socio-economic policies, the existence of a truly transnational mode of solidarity (Florini, 2000; Khagram et al., 2002), however marginal or fragile, seems not only possible, but tangible. This is not to dismiss the reality that most forms of organised solidarity may be nationally embedded. On the contrary, even those organisations which have identifiable transnational dimensions may be rooted in the local as opposed to the global. These organisations that are engaged in transnational solidarity may operate across the boundaries of the national and transnational and, consequently, our efforts to investigate these forms of solidarity learned to embrace such nuance.

The chapter unfolds as follows: in Section 4.2, we present our research methods after which we discuss our findings, firstly, by considering the forms of solidarity (4.2.1), and secondly, its territorial scope (4.2.2). Finally, in Section 4.3, we elaborate the conclusions we have drawn from our analysis. 


\subsection{RESEARCH DESIGN}

To properly examine the existence of transnational solidarity in Europe - and by solidarity we mean, as specified in Chapter 1 of this volume, "dispositions and practices of mutual help or support, be that by personal contributions or by the active support of activities of others, tied to informal and/or institutionalised groups" - we undertook an approach that sought to answer two key research questions: (i) How is solidarity operationalised across Europe? (ii) What scales of action are solidarity organisations engaged in across Europe? To begin to answer these questions we conceptualised transnational solidarity as a spatial dimension resulting from three sets of intertwined factors related to civil society organisations: (a) organisational formal structures, that is, those functional dimensions of organisations that allow them to operate in policy advocacy and service delivery, such as human resources, funding, decision making mechanisms; (b) organisational activities, including the range of actions organisations are involved in, with a particular focus on specific campaigns and events connected to the three fields of disability, unemployment and migration/ asylum; and (c) relational dimensions, that constitute organisations' social and political connections and networks (Figure 4.1 summarises our research framework).

Building on this conceptualisation, we then turned to our unit of analysis; those organisations operating in this space - which we define as Transnational Civil Society Organisations (TCSOs). Our research design focused upon organised solidarity occurring at the edges between national and transnational boundaries to ascertain the degree of solidarity at the

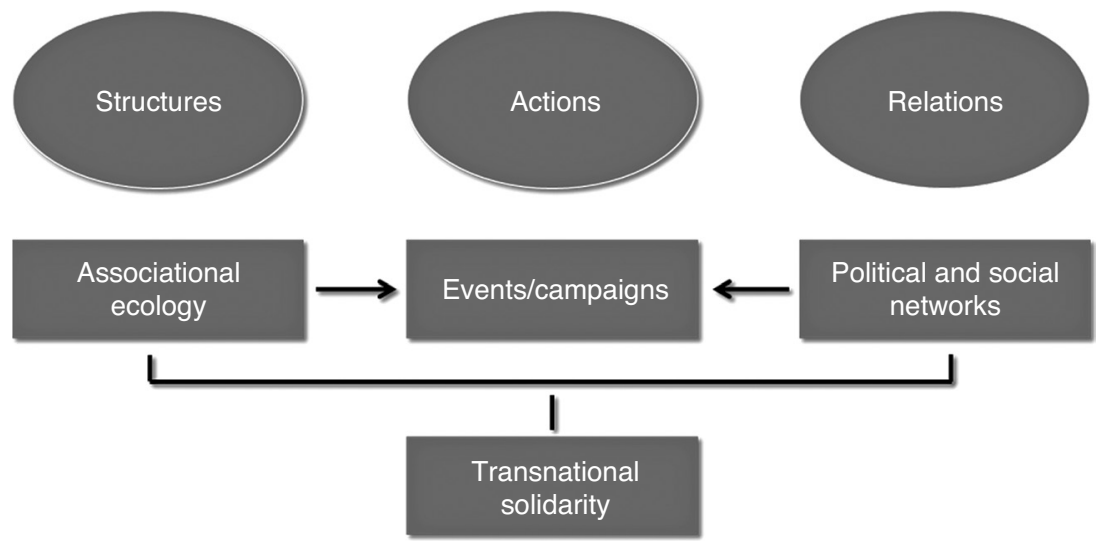

Figure 4.1 Research design framework to study TCSOs 
national and supranational levels while capturing the different dimensions such collective action might involve. In doing so, we pursued a sampling strategy to uncover the most relevant and cutting-edge examples of how solidarity is operationalised. To accomplish this, we relied upon two sources to provide us with research participants. For interviews conducted by our colleagues across the eight European countries of our study, we asked teams to sample those organisations based in their country that could be drawn from the memberships of transnational umbrella organisations and networks. Following this sampling approach, teams conducted at least 30 interviews per country comprising at least ten interviews across each of the fields that formed the focus of the TransSOL project: migration, disability or unemployment. In addition, three campaigns that were either monothematic and thus focused upon one of the three issue fields (e.g. decriminalising solidarity on migration/asylum; European day of persons with disabilities) or those that were cross-thematic (e.g. the Transnational Social Strike operates across employment and migration) formed the focus of further interviews by three dedicated teams from each of the eight countries. In this chapter we focus exclusively on interviews conducted by the eight teams across Europe. The findings from our research on transnational campaigns have been published as part of the broader TransSOL study (Baglioni and Montgomery, 2017).

Building upon the extensive experience of the teams in conducting research into civil society organisations, a survey design process was initiated during which teams were consulted for their expertise in the field and to draw upon their methodological skills. Pre-tests took place to ascertain the effectiveness of the survey design and to identify any issues prior to its deployment across all participating countries. The 245 interviews we conducted with TCSOs can be best described in three parts: (i) an open ended question format to capture information from interviewees on the participation of their organisations in joint events and campaigns; (ii) the composition of organisations and their operational scope; and (iii) working with interviewees to identify the relationships their organisation had with other civil society organisations and institutions. Although the findings in this chapter are informed by the open-ended questions in our survey, the focus of our analysis are those questions that reveal the ways in which TCSOs operationalise solidarity in connection with the welfare state, in their everyday work, and the territorial scope of their operations.

\subsubsection{Findings I: The Shape of Solidarity}

We begin our analyses by revealing the extent of the activation of TCSOs on welfare-state issues across the eight European countries of our study. 
Table 4.1 Providing assistance in access to the welfare system

\begin{tabular}{lccc}
\hline & Often $(\%)$ & Seldom $(\%)$ & Never $(\%)$ \\
\hline Denmark & 73 & 3 & 0 \\
France & 61 & 15 & 9 \\
Germany & 33 & 17 & 0 \\
Greece & 67 & 10 & 0 \\
Italy & 90 & 7 & 0 \\
Poland & 50 & 7 & 0 \\
Switzerland & 33 & 13 & 7 \\
UK & 56 & 6 & 0 \\
Total & 58 & 10 & 2 \\
\hline
\end{tabular}

Note: $\quad(\mathrm{N}=245)$

Table 4.1 provides evidence regarding the salient role civil society actors perform in the promotion of solidarity when this is connected with the welfare state: almost two thirds of TCSOs provide assistance with accessing the welfare state on a regular basis and another $10 \%$ does so from time to time. Moreover, Table 4.1 reveals that the complementary welfare state action of TCSOs is not only relevant in countries with less generous welfare regimes such as Italy and Greece (where respectively $90 \%$ and $67 \%$ of TCSOs interviewed provide assistance with accessing the welfare state system) but also in countries with relatively more generous welfare provisions, such as Denmark (73\% of TCSOs provide support with accessing welfare services). This high frequency of interactions with the welfare system may speak also to the sometimes complex, bureaucratic and conditional welfare regimes that claimants must navigate when accessing support to meet their basic needs. This means that the type of solidarity promoted by TCSOs is not only expressed through the provisions of services, it is also involved in facilitating access to services directly provided by public bodies. Hence, TCSOs are engaged in an activity which contributes to solidarity by enabling citizens experiencing a variety of needs to enforce their right to support.

Table 4.2 complements our understanding of the welfare-state related contribution to solidarity that TCSOs provide by revealing how civil society organisations support vulnerable individuals in need by providing in-kind help such as meals, clothes, and accommodation which would usually be provided by public anti-poverty programmes. Table 4.2 shows that one in every four organisations provides such in-kind services on a regular basis, and that more than one in every ten does so occasionally. The provision of in-kind services is more salient in countries such as Greece that are 
Table 4.2 Providing assistance: in-kind support (e.g. meals, accommodation, clothes)

\begin{tabular}{lccc}
\hline & Often $(\%)$ & Seldom $(\%)$ & Never $(\%)$ \\
\hline Denmark & 27 & 10 & 63 \\
France & 30 & 15 & 39 \\
Germany & 10 & 13 & 73 \\
Greece & 43 & 27 & 30 \\
Italy & 30 & 10 & 60 \\
Poland & 37 & 10 & 53 \\
Switzerland & 13 & 20 & 60 \\
UK & 13 & 22 & 66 \\
Total & 25 & 16 & 56 \\
\hline
\end{tabular}

Note: $\quad(\mathrm{N}=245)$

experiencing difficult circumstances, but is still not negligible in welfare generous and affluent countries such as Denmark, France and Italy, where a third of TCSOs provide these services regularly or occasionally. These findings highlight the complementary role that TCSOs play in engaging in solidarity with individuals in crisis across the eight European countries of our study. They also raise questions about the capacities of such organisations to sustain their operations in case of (in some cases further) cuts to the very public budgets which help to keep their organisations open and meet the needs of vulnerable groups (Federico, 2018), particularly given that such cuts would serve only to increase the numbers of vulnerable people requiring assistance from these same TCSOs.

Table 4.3 provides an estimation of the magnitude of solidarity via TCSOs by presenting the number of beneficiaries that such organisations reach with their welfare-state related services: $40 \%$ of our samples offer services on a yearly basis to a large number of beneficiaries (more than 1000), with some of these reaching even a much larger share of the population in need. There is evidence therefore in Table 4.3 of an active solidarity that reaches out to a large share of people in need through the various forms of pro-welfare state action.

What Tables 4.1, 4.2 and 4.3 confirm is the contribution that TCSOs are making in keeping solidarity alive when welfare state services are at stake and even more so in a period of economic crisis and austerity. They provide vivid evidence of the welfare-mix (Evers, 1995) which has been described as reflective of contemporary European welfare systems, where a mixture of public and private actors provides a range of services, in a diversified legal pattern across different contexts. 
Table 4.3 How many persons (beneficiaries) overall obtained services in the last year?

\begin{tabular}{lcccccc}
\hline & $\begin{array}{c}\text { None } \\
(\%)\end{array}$ & $\begin{array}{c}\text { Less than } \\
100(\%)\end{array}$ & $\begin{array}{c}\text { Less than } \\
500(\%)\end{array}$ & $\begin{array}{c}\text { Less than } \\
1000(\%)\end{array}$ & $\begin{array}{c}\text { More than } \\
1000(\%)\end{array}$ & $\begin{array}{c}\text { Don't } \\
\text { Know }(\%)\end{array}$ \\
\hline Denmark & 7 & 7 & 20 & 10 & 50 & 7 \\
France & 0 & 18 & 15 & 9 & 55 & 3 \\
Germany & 0 & 17 & 10 & 20 & 27 & 27 \\
Greece & 0 & 17 & 33 & 10 & 30 & 10 \\
Italy & 0 & 7 & 23 & 13 & 53 & 3 \\
Poland & 0 & 17 & 17 & 17 & 30 & 20 \\
Switzerland & 0 & 17 & 20 & 3 & 37 & 23 \\
UK & 0 & 6 & 25 & 9 & 41 & 19 \\
Total & 1 & 13 & 20 & 11 & 40 & 14 \\
\hline
\end{tabular}

Note: $\quad(\mathrm{N}=245)$

\subsubsection{Findings II: The Scope of Solidarity}

Our analysis of the transnational involvement of TCSOs for solidarity purposes now turns to the consideration of their (territorial) scope of action. Earlier in this chapter, we observed that solidarity when essential welfare state services are at stake is heavily dependent upon the actions of civil society organisations. But to what extent does this activism vis-à-vis the unemployed, migrants, asylum seekers and refugees, expand beyond local and national boundaries? Given that welfare state regimes are still defined by national territorial and political boundaries - in the sense that beneficiaries of welfare services are those living within the boundaries of a given state - do we have evidence of solidaristic actions that transcend boundaries in the name of common needs and transnational challenges? Moreover, do we have evidence that supports those analyses that the opportunities provided in Europe for the de-nationalisation and Europeanisation of the welfare state have resulted in transnational solidarity?

Table 4.4 provides an overview of the different territorial levels at which civil society organisations can deploy their activities, ranging from the local, to the regional, national, and finally European and transnational (representing those activities occurring inside and outside the EU) levels. For the purposes of this chapter, we consider as activities occurring at the transnational level those which occur both at the European (across Europe) and at the transnational (in and outside the EU) level. As Table 4.4 shows, if we read the 'total' row, one in every two civil society organisations is active at the transnational level $(53.9 \%$ at $\mathrm{EU}$, and $48.6 \%$ at transnational 
Table 4.4 In which of these geographical areas is your organisation/group active?

\begin{tabular}{llcccc}
\hline & $\begin{array}{c}\text { Local } \\
(\%)\end{array}$ & $\begin{array}{c}\text { Regional } \\
(\%)\end{array}$ & $\begin{array}{c}\text { National } \\
(\%)\end{array}$ & $\begin{array}{c}\text { EU } \\
(\%)\end{array}$ & $\begin{array}{c}\text { Transnational* } \\
(\%)\end{array}$ \\
\hline Denmark & 63.3 & 66.7 & 96.7 & 86.7 & 63.3 \\
France & 69.7 & 75.8 & 81.8 & 57.6 & 57.6 \\
Germany & 23.3 & 33.3 & 90 & 40 & 43.3 \\
Greece & 36.7 & 46.7 & 73.3 & 36.7 & 30 \\
Italy & 76.7 & 66.7 & 76.7 & 50 & 56.7 \\
Poland & 56.7 & 53.3 & 86.7 & 76.7 & 66.7 \\
Switzerland & 50 & 63.3 & 66.7 & 43.3 & 33.3 \\
UK & 81.3 & 56.3 & 62.5 & 40.6 & 37.5 \\
Total & 57.6 & 58 & 79.2 & 53.9 & 48.6 \\
\hline
\end{tabular}

Note: * Transnational here refers to activism inside and outside the European Union $(\mathrm{N}=245)$

level). Given that our sample focused on those organisations which were part of supranational umbrella organisations, we would have expected to find a higher share of TCSOs to be engaged in solidarity actions beyond their own national borders. Therefore, the first lesson we learn from Table 4.4 is that for civil society organisations, including those that are part of transnational networks and campaigns, the national level remains the most salient geo-political spatial dimension at which to act (the national level of action is by far the most popular choice of our TCSOs, with close to $80 \%$ of them affirming that they operate at that level). Hence, solidarity, when understood through the provision of services related to the welfare state, remains an issue of national scope, thus suggesting that the argument from some scholars that the decoupling of the welfare state from the national state remains far from reality. Further reinforcing the importance of the country level of action, Table 4.4 also shows that slightly more than one in every two organisations is active at sub-state levels as well (both local and regional) and that these scales of activity are at least as, if not slightly more, important than the EU level for the TCSOs in our study (a finding made all the more significant when considering that the TCSOs we interviewed across the eight European countries were sampled based on their membership of transnational umbrellas and networks).

Moreover, Table 4.4 reveals that the situation is more nuanced if we consider cross-country differences: Danish and Polish TCSOs lead the group on European and transnational level activities, while Greek, German, British and Swiss organisations appear to be less inclined to engage 
Table 4.5 Action types by geo-political level

\begin{tabular}{lcc}
\hline & $\begin{array}{c}\text { National } \\
(\%)\end{array}$ & $\begin{array}{c}\text { Transnational* } \\
(\%)\end{array}$ \\
\hline Political education of citizens/raising awareness & 89 & 28 \\
Services to members (e.g. counselling; material & 81 & 14 \\
$\quad$ support) & 79 & 36 \\
Interest representation/Lobbying institutions & 79 & 31 \\
Participation in legal consultations/policy making & 69 & 20 \\
Mobilising members through direct action & 64 & 20 \\
Fundraising & 61 & 17 \\
Services to others (e.g. clients) & 51 & 20 \\
Mobilising members through protest/demonstrations & & \\
\hline
\end{tabular}

Note: * Transnational here refers to activism inside and outside the European Union $(\mathrm{N}=245)$

across their country borders, while French and Italian TCSOs occupy an intermediary position. A deeper analysis of the transnational activism of Danish TCSOs is, in part at least, explained by the connection and activation of these TCSOs through Scandinavian networks rather than through EU-based ones. When a similar scrutiny is placed upon the Polish case, the high degree of Polish transnational (particularly EU level) activism may reflect the country's engagement with the EU in terms of access to regional development-related funding. Otherwise, it may also reveal the difficulties that Polish civil society organisations are facing at home in their relationships with a government which approaches migration, asylum, disability and unemployment, our TCSO fields of action, with a conservative policy frame (Szczupak and Petelczyc, 2017).

The prominence of the national level also emerges when considering the spatial distribution of TCSOs' activities. Table 4.5 shows that no matter which specific activity an organisation deploys (it can be a political-related one such as political education of citizens, or a service delivery-focused one, such as offering counselling services or material support) in each case the national level largely overshadows the transnational one. In the case of service delivery and material support it is understandable that TCSOs with scarce resources do not aim to deliver such services on a cross-border scale (Baglioni and Montgomery, 2017) and welfare states services provision remains bound to national resources and policy frameworks, but in terms of raising awareness (although resources will of course play a role here) it is still perhaps not the full story given that in a digitally interconnected age the transnational level is very much a secondary priority to the national 
level. Somewhat unsurprisingly, activities that imply an active mobilisation of membership (in Table 4.5 these are mobilising members through direct actions and mobilising members through protest/demonstrations) essentially occur at the national level: in contrast with literature having advocated for the existence of a European public sphere for political collective mobilisation (Imig and Tarrow, 2001; Chabanet, 2008), it seems that our TCSOs are still much more focused on mobilising members at the national level rather than at the transnational one.

Another intriguing finding of Table 4.5 is the poor number of organisations that look at the transnational and European levels of action for fundraising: only one in every five organisations declares that it undertakes fundraising activities at the transnational level while two thirds carry out fundraising at the national level. Given the importance of securing finance to the sustainability of TCSOs we might conclude that the strong focus on the national level will not disappear if we add in the analysis of other organisational dimensions. In fact, organisations in constant need of funding will likely focus their capacity and resources for action at the spatial level where they can expect such funding to have the greatest impact and where future funding streams are most readily available. Moreover, as we have seen in our earlier section on findings, most organisations focus their activities on welfare state-related provision, which remains primarily deployed within their countries' boundaries, in support of people that might also be of a different nationality, but that are still based within the country where a given organisation is based.

In sum, we might predict that our TCSOs act at the national level more than at the transnational one because their audience is, in many senses (funding-wise, policy-wise, and beneficiary-wise), national more than transnational.

If we consider the sources of funding for TCSOs (Table 4.6), we see that national level donors (in this case, 'Grants from national governments') are more than twice as important as European grants, which is consistent with our earlier findings. Again, there are differences among countries: French and Polish TCSOs show a higher interest in pursuing, or a greater reliance upon transnational (European) grants than TCSOs in the other countries as they comprise more than a third of the civil society organisations for whom European grants are very important for everyday action. Actually, for Polish organisations European funding is as relevant as national government funding: in fact, due to the strong political polarisation promoted by the centreright government, many TCSOs that oppose government policies need recourse to EU funding in order to survive, given that they are precluded from government funds. In Greece, funding emanating from the EU largely supersedes funds from national government, perhaps as a consequence of 
Table 4.6 Share (\%) of TCSOs for whom national and EU level grants are very relevant for survival

\begin{tabular}{lcc}
\hline & National Government Grants (\%) & EU Grants (\%) \\
\hline Denmark & 80 & 13 \\
France & 45 & 36 \\
Germany & 50 & 7 \\
Greece & 7 & 20 \\
Italy & 27 & 10 \\
Poland & 37 & 33 \\
Switzerland & 37 & 3 \\
UK & 13 & 9 \\
Total & 37 & 17 \\
\hline
\end{tabular}

Note: $\quad(\mathrm{N}=245)$

the reduced capacity of the Greek state to subsidise civil society due to the critical situation of its public budget. For the remaining countries, national governments still provide a quite relevant source of economic resources not comparable with the transnational one (in Denmark $80 \%$ of organisations access national grants while only $13 \%$ consider EU grants as very important; similarly in Germany, one in every two organisations relies upon national grants, while less than one in ten considers EU-level funding as very relevant). Aside from Greece, one other country where national government grants were less relevant was in the UK, where our national-level analysis revealed a fragmented landscape of funding with numerous organisations relying upon a portfolio of funding sources, including charitable trusts, to sustain themselves. This is in a context where funding for local authorities has been at the forefront of austerity measures implemented since 2010 .

Another indicator we examine to assess the capacity of TCSOs to engage in transnational solidarity is whether or not they are part of consultative policy-making processes at various spatial levels. Solidarity, therefore, is not just expressed through front-line service delivery activities but is also promoted by TCSOs through their efforts to generate policy change and (re)shape the policy environment so that it better meets the needs of vulnerable people. Table 4.7 provides an overview of this indicator: overall, once again, the national level is more relevant than the European one as an arena for policy engagement. Also, the subnational one is overall a political-spatial level where TCSOs are engaged in policy advisory functions. However, if we consider the situation among countries, again, there are interesting differences to be noted. Firstly, consistent with our earlier results pointing to the importance of the EU for the fundraising 
Table 4.7 TCSOs' participation with a consultative status in policymaking procedures at different spatial levels

\begin{tabular}{lccc}
\hline & $\begin{array}{c}\text { EU } \\
\text { consultative (\%) }\end{array}$ & $\begin{array}{c}\text { National } \\
\text { consultative (\%) }\end{array}$ & $\begin{array}{c}\text { Subnational } \\
\text { consultative (\%) }\end{array}$ \\
\hline Denmark & 17 & 80 & 40 \\
France & 39 & 61 & 51 \\
Germany & 53 & 53 & 30 \\
Greece & 33 & 53 & 60 \\
Italy & 47 & 70 & 80 \\
Poland & 63 & 77 & 60 \\
Switzerland & 20 & 57 & 50 \\
UK & 34 & 69 & 63 \\
Total & 38 & 65 & 54 \\
\hline
\end{tabular}

Note: $\quad(\mathrm{N}=245)$

activities of Polish TCSOs, Table 4.7 reveals that Polish TCSOs are highly engaged at the EU policy consultative level (63\% of those we interviewed in Poland say that they are consulted systematically on policy issues by EU bodies). Secondly, there are some differences between the results in Table 4.7 and earlier tables: while in earlier tables (e.g. Table 4.4), Danish TCSOs appeared to be more engaged at the transnational level than German TCSOs, in Table 4.7 we see that one in every two German organisations is consulted by an EU body during ad hoc policy-making procedures, and the same occurs with Italian TCSOs, while less than one fifth of Danish organisations are consulted in EU policy-making processes, despite Table 4.4 having shown that $87 \%$ of Danish TCSOs were active at the EU level.

In sum, there is no direct correspondence between those TCSOs that undertake action at the transnational level and those that, although focusing on nationally bounded solidarity activities, are still considered valuable interlocutors in policy processes in Brussels and are therefore invited to provide advice during a policy-making procedure. This is an outcome we should consider in greater depth as it may have implications for how we interpret transnational activism, drawing our attention to the existence of different shades of transnational activism and different types of organisations engaged at the transnational level: some more openly focused on supranational policy issues and arenas, others more concerned with their own country's situation but still open to engage, if invited and on an ad hoc basis, also at transnational level.

In fact, when we discussed with TCSOs their experiences of working at the transnational level, most of them did appreciate acting across state 
boundaries as an opportunity of mutual learning, and also as a viable way to strengthen their voice vis-à-vis policy makers and stakeholders. Moreover, activities done at transnational level seem somehow less exposed to intra-TCSO competition, and as such are appreciated for their fostering cooperation and reciprocal support. However, three factors have been noted as obstructions to further engagement at transnational level: the diversity of circumstances among European countries; the different welfare states and social protection models in the three policy fields covered by TransSol; and the fact that working across state boundaries requires substantial human and economic resources and even the overcoming of language barriers.

\subsection{CONCLUSION}

This chapter has provided evidence about the existence of a range of activities that TCSOs engage in - primarily in connection to (a weakened degree of publicly funded) interventions in welfare state issues - that speak about solidarity as an act of support in meeting people's needs. Furthermore, what our findings indicate is a paradox between the issues confronting the vulnerable groups of our study and the gap in transnational solidarity among the TCSOs we interviewed. On the one hand, the economic crisis, the Eurozone crisis and the austerity measures which followed are essentially transnational issues themselves that involve transnational actors. Moreover, the so-called refugee crisis (although perhaps better understood as a tragedy for the refugees and perceived as a border crisis in Europe) is a transnational issue at its core that can only be properly addressed through multilateral action. Despite our best efforts to target organisations that are active across countries through being part of a specific transnational umbrella organisation or network, this chapter reveals that we have found limited evidence of transnational dimensions of solidarity. Of course, in some of our countries, namely Denmark and Poland, there is evidence of a degree of engagement by TCSOs which operate across spatial-political levels, including the transnational or European levels. In most of the other countries, although cross-border activities are not rare (roughly one in every two organisations does operate transnationally on a cross-country average), their scope of action remains heavily centred on the national (and also the sub-national) level. Our understanding of these findings is that civil society organisations will likely act at those spatial-political levels, where they understand their beneficiaries and their key political interlocutors to be located: therefore, if a TCSO decides that for a specific issue or mission goal, the key institutional or political interlocutors are 
located at the European level, they will likely engage at the transnational level, while if, due to their specific field of action, and even more so if they work on welfare state-related services and needs, they consider it to be more effective or strategic to address authorities at a different (e.g. national or subnational) level, their action will primarily develop across these levels.

Overall, it is clear from our interviews across eight European countries that the more formalised or institutionalised component of civil society organisations active in the fields of unemployment, migration, and disability, as formal expressions of solidarity, remain bounded to their national contexts. However, as discussed in this book (e.g. Chapter 8), we have found evidence of horizontal transnationalisation (Lahusen et al., 2018) among the more grass roots-based and informal models of collective action and civil society. Civil society-led transnational solidarity comes at a time when reactionary parties and xenophobic movements are on the rise in Europe and beyond, and therefore our findings act as a signal that efforts to construct a truly transnational civil society may be more necessary than they have been before.

\section{REFERENCES}

Baglioni, S. (2015). Multi-Level Governance, the EU and Civil Society: A Missing Link? In E. Ongaro (ed.), Multi-Level Governance: The Missing Linkages. Bingley: Emerald Group Publishing, pp. 163-82.

Baglioni, S. and Montgomery, T. (2017). Integrated Report on Collective Forms of Solidarity at Times of Crisis (WP4). TransSOL project (https://transsol. $\mathrm{eu} /$ ).

Brandsen, T., Pestoff, V., Verschuere, B., Defourny, J. and Hulgård, L. (2014). Co-Production and the Third Sector: The State of the Art in Research. In J. Defourny, L. Hulgård and V. Pestoff (eds), Social Enterprise and the Third Sector: Changing European Landscapes in a Comparative Perspective. London: Routledge, pp. 231-49.

Chabanet, D. (2008). When the Unemployed Challenge the European Union: The European Marches as a Mode of Externalization or Protest. Mobilization, 13(3): 311-22.

Evers, A. (1995). Part of the Welfare Mix: The Third Sector as an Intermediate Area. Voluntas, 6(2): 159-82.

Federico, V. (2018). Conclusion: Solidarity as a Public Virtue? In V. Federico and C. Lahusen (eds), Solidarity as a Public Virtue? Law and Public Policies in the European Union. Baden-Baden: Nomos Publishing, pp. 495-542.

Ferrera, M. (2005). The Boundaries of Welfare: European Integration and the New Spatial Politics of Social Protection. Oxford: Oxford University Press.

Florini, A. M. (ed.) (2000). The Third Force: The Rise of Transnational Civil Society. Tokyo: Japan Centre for International Change.

Greenwood, J. (2007). Organized Civil Society and Democratic Legitimacy in the European Union. British Journal of Political Science, 37(2): 333-57. 
Imig, D. and Tarrow, S. (eds) (2001). Contentious Europeans: Politics and Protest in a Composite Polity. Lanham, MD: Rowman \& Littlefield.

Khagram, S., Riker, J. V. and Sikkink, K. (eds) (2002). Restructuring World Politics: Transnational Social Movements, Networks, and Norms. Minneapolis: University of Minnesota Press.

Lahusen, C. (2014). Mind the Gap: Local Civil Society Organizations and the European Union. In S. Baglioni and M. Giugni (eds), Civil Society Organizations, Unemployment, and Precarity in Europe. Basingstoke: Palgrave Macmillan, pp. 204-28.

Lahusen, C., Kousis, M., Zschache, U. and Loukakis, A. (2018). European Solidarity in Times of Crisis: Comparing Transnational Activism of Civic Organisations in Germany and Greece. Österreichische Zeitschrift für Soziologie, 43(1): 173-97.

Leibfried, S. and Pierson, P. (eds) (1995). European Social Policy: Between Fragmentation and Integration. Washington, DC: The Brookings Institution.

Montgomery, T. and Baglioni, S. (2018). Solidarity in Austerity Britain: The Cases of Disability, Unemployment and Migration. In V. Federico and C. Lahusen (eds), Solidarity as a Public Virtue? Law and Public Policies in the European Union. Baden-Baden: Nomos Publishing, pp. 469-94.

Musso, P. (2015). La solidarité: généalogie d'un concept sociologique. In A. Supiot (ed.), La Solidarité. Enquête sur un principe juridique. Paris: Odile Jacob, pp. 93-123.

Smismans, S. (2003). European Civil Society: Shaped by Discourses and Institutional Interests. European Law Journal, 9(4): 482-504.

Supiot, A. (ed.) (2015). La Solidarité. Enquête sur un principe juridique. Paris: Odile Jacob.

Szczupak, K. and Petelczyc, J. (2017). Transnational Solidarity in Polish Civil Society: Research Report Submitted as a Delivery of the EU-Funded Project TransSOL. TransSOL project (https://transsol.eu/).

Van Deth, J. W. (2008). European Civil Society: The Empirical Reality in the Multi Level System of the EU. In B. Kohler-Koch, D. De Bièvre and W. Maloney (eds), Opening EU Governance to Civil Society: Gains and Challenges. Connex Report Series N. 05.

Warleigh, A. (2001). Europeanizing Civil Society: NGOs as Agents of Political Socialization. Journal of Common Market Studies, 39(4): 619-39. 